\title{
Carbon fiber reinforced magnesium alloy in a Ti-6Al-4V shell
}

\author{
Vasily Astanin ${ }^{1, *}$, Daniya Nurullina ${ }^{1}$, Adel Zaripova ${ }^{1}$, Pavel Soloviev $^{1}$, and Fanil Musin ${ }^{1}$ \\ ${ }^{1}$ Ufa State Aviation Technical University, 450008 Karl Marx str. 12, Ufa, Russia
}

\begin{abstract}
Continuous carbon fiber reinforced magnesium alloy pieces in SMC Ti-6Al-4V shell have been fabricated using pressure infiltration. Similar temperatures $\left(\sim 700^{\circ} \mathrm{C}\right)$ for superplastic formation of the shell and melting of the alloy allow this to be done in one step. The quality of infiltration of the molten alloys is found to be proportional to load. A limiting parameter in increasing the infiltration pressure is the strength of the welded bonds. Structure, fracture parameters and mechanical properties are discussed.
\end{abstract}

\section{Introduction}

Lightweight composite materials have attractive properties and, thus, are attractive for manufacturing of critical components and parts of aviation and space technology, power and transport devices. High specific strength and specific Young modulus give advantages, and metal matrix composites (MMC) also have good electrical and thermal conductivity.

Magnesium and aluminium alloys are the most promising ones to be applied as matrix material. According to many researchers, magnesium alloys have an advantage over aluminium, because they have a lower density [1]. Despite the fact that it is traditionally believed that magnesium alloys have low corrosion and erosion resistance, which makes it difficult to use MMC based on them, some sources show better corrosion resistance of magnesium alloys than aluminium ones $[2,3]$.

Low density of components and high strength of carbon fibers provide MMC with significant advantages over traditional titanium alloys [3, 4]. Magnesium alloys have one more feature - the low Young modulus, which is a drawback when using non-reinforced magnesium alloys, but being as part of MMC, magnesium alloys, therefore, have a damping ability and help to reduce the level of vibrations and noise that occur during operation of products.

Thus, MMCs based on magnesium alloys reinforced with carbon fibers are very promising for such products as aircraft engine compressor blades $[1,5]$.

\section{Experimental}

\subsection{Materials and methods}

The properties of magnesium impose requirements to its processing method. Both magnesium and its alloys have excellent fluidity, low melting point $\left(\sim 650^{\circ} \mathrm{C}\right)$, which makes them an excellent choice for casting. However, active interaction with oxygen requires protection by inert gases during processing.

The choice of a particular magnesium alloy to produce a composite is due to the following factors: its strength, cast properties and good adhesion to carbon fiber. The first two factors are fairly obvious and are determined by the doping system, and the latter should be considered in more detail. Liquid magnesium alloy itself does not wet carbon fibers either at atmospheric pressure or in low vacuum, and does not form a chemical bond with it. One can overcome this problem through use of magnesium alloy with moderate $(8-10 \%)$ aluminum content. Aluminum, in contrast to magnesium, reacts actively with carbon fiber to form needle particles of $\mathrm{Al}_{4} \mathrm{C}_{3}$ carbides, which both provide fiber and matrix coupling. It is noted that higher aluminum content in the alloy is undesirable, since it leads to the growth of carbides to the size critical for impact properties and degradation of the fiber [6]. Thus, alloys of the AZ91 family and their common Russian counterpart ML5 are suitable for composite formation. AZ91magnesium alloy is used as the matrix material in the present research.

Table 1. Chemical composition of common $\mathrm{Mg}$ alloys $[7,8]$

\begin{tabular}{|c|c|c|c|c|}
\hline Alloy & Al & Zn & Mn & other \\
\hline AZ91D & $8.3 \ldots 9.7$ & $0.35 \ldots 1.0$ & $0.15 \ldots 0.5$ & $\sim 0.10$ \\
\hline ML5 & $7.5 \ldots 9.0$ & $0.2 \ldots 0.8$ & $0.15 \ldots 0.5$ & $<0.5$ \\
\hline
\end{tabular}

When working under difficult conditions, protective edges and casings are used to protect composite materials from external impact. The protective shell can be made in the form of coating of a finished product, or it can be formed from the technological process in the production process.

The original method used in this work consists in fabrication of composite material directly in the nonremovable titanium shell, which is thin and strong. This makes possible accurate reproduction of the shell

*Corresponding author: v.astanin@gmail.com 
complex shape in the manufacturing process, so as not to increase substantially the product mass. These requirements are satisfied by thin sheets of Ti-6Al-4V alloy with submicrocrystalline (SMC) structure. The strength of the Ti-6Al-4V alloy in this state reaches 1350 $\mathrm{MPa}$, and the superplastic deformation temperature, at which the product molding is facilitated, is reduced from $900{ }^{\circ} \mathrm{C}$ to $600 \ldots 700{ }^{\circ} \mathrm{C}$ [9]. This temperature range is in good agreement with the melting point of magnesium alloy AZ91, the liquidus point of which is $650^{\circ} \mathrm{C}$.

The technology of composite products in shells assumes the production of ultrafine-grained sheets; tight welding of the shell ensuring the weld seam strength at the level of the base material strength; precise molding, which does not require further machining, except polishing; complete infiltration of the composite, which requires vacuum and sufficient pressure of the melt; compatibility of components by the criteria of equal strength, thermal expansion and bond strength at the interfaces $[10,11,12]$.

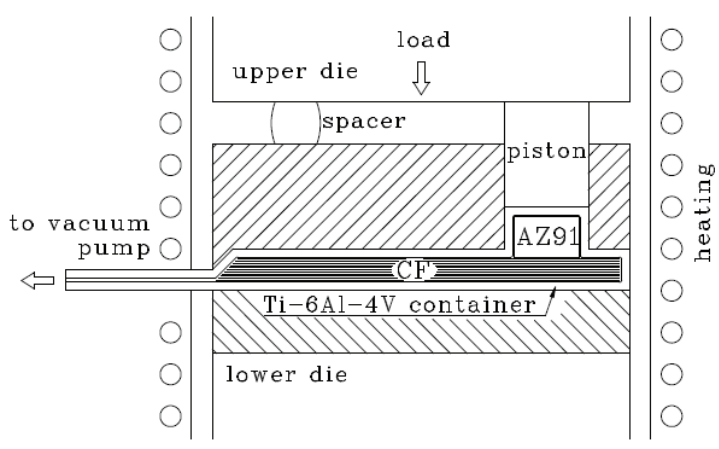

Fig. 1. Set-up of infiltration method.

The first problem is successfully solved by isothermal rolling under the conditions of low-temperature superplasticity [13]. The solutions of the others are shown in this paper, the main idea of which is to conduct all technological operations at the same temperature and in one cycle, which is possible due to the nanostructured state of the titanium alloy.

The initial rod of Ti-6Al-4V alloy was subjected to allround forging with the decreasing temperature [13]. The produced billets were rolled on an isothermal rolling mill and then subjected to creep annealing. As a result, a structure was formed consisting of equiaxed fragments with an average size of $160 \mathrm{~nm}$.

Table 2. Mechanical properties of the SMC Ti-6Al-4V alloy at elevated temperatures in the rolling direction.

\begin{tabular}{|c|c|c|}
\hline $\mathbf{T},{ }^{\circ} \mathbf{C}$ & $\boldsymbol{\sigma}_{\max }, \mathbf{M P a}$ & $\boldsymbol{\delta}, \boldsymbol{\%}$ \\
\hline 550 & 310 & 300 \\
\hline 600 & 110 & 430 \\
\hline 700 & 45 & 720 \\
\hline
\end{tabular}

The produced material exhibits superplasticity in the temperature range $550-700{ }^{\circ} \mathrm{C}$. The mechanical properties of such material at elevated temperatures are given in Table 1.

Carbon fibers UKN-5000 with no coating with a tensile strength of $3000 \mathrm{MPa}$ were used.

\subsection{Production of composite material in a container}
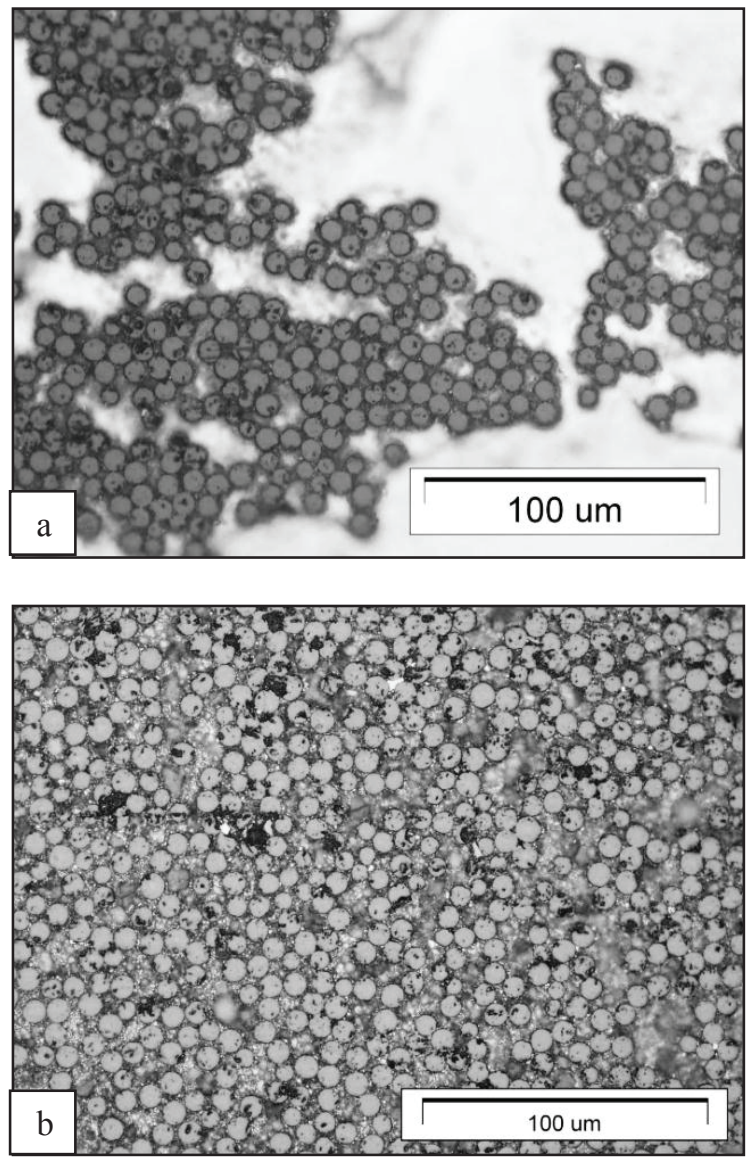

Fig. 2. Microstructure of AZ91 - UKN-5000 composite in case of insufficient (a), in case of sufficient pressure (b).

The container samples are subjected to superplastic molding to form cavities for the carbon fiber prepreg and the magnesium alloy billet. During assembly, parts of the container are hermetically sealed around the perimeter by contact welding, then by argon-arc welding. The air is evacuated through the nozzle of the container placed in the mold, and then the container is heated in an electric furnace installed on the electromechanical press. A load was applied after heating at a temperature higher than the melting point of magnesium alloy. The vacuum was maintained as low as $10^{-2}$ bar throughout the cycle until the load was removed.

The described method of composite material fabrication is protected by a patent [14].

\subsection{Microstructure and properties of the composite material}

Infiltration under pressure resulted in the titanium shell bonded with the magnesium matrix, which, in turn, penetrated the inter-fiber space. No pores and 
detachments were found at the interface of the matrixtitanium alloy. The latter could appear as a result of thermal stresses during the cooling of the packet due to the difference in the thermal expansion of titanium and magnesium.

Apparently, in the process of cooling under pressure, thermal stresses can relax due to deformation of the magnesium alloy.

At low pressure magnesium melts practically do not wet carbon fibers $[6,11]$, which prevents successful infiltration and leads to the formation of inter-fiber voids. The fibers are assembled into bundles within which they come into contact, and the matrix remains on the periphery of the bundles (Fig. 2, a). Such a structure does not contribute to fabricated full value composite. Overcoming the forces of surface tension was achieved by selecting the temperature and pressure (Fig. 2, b).
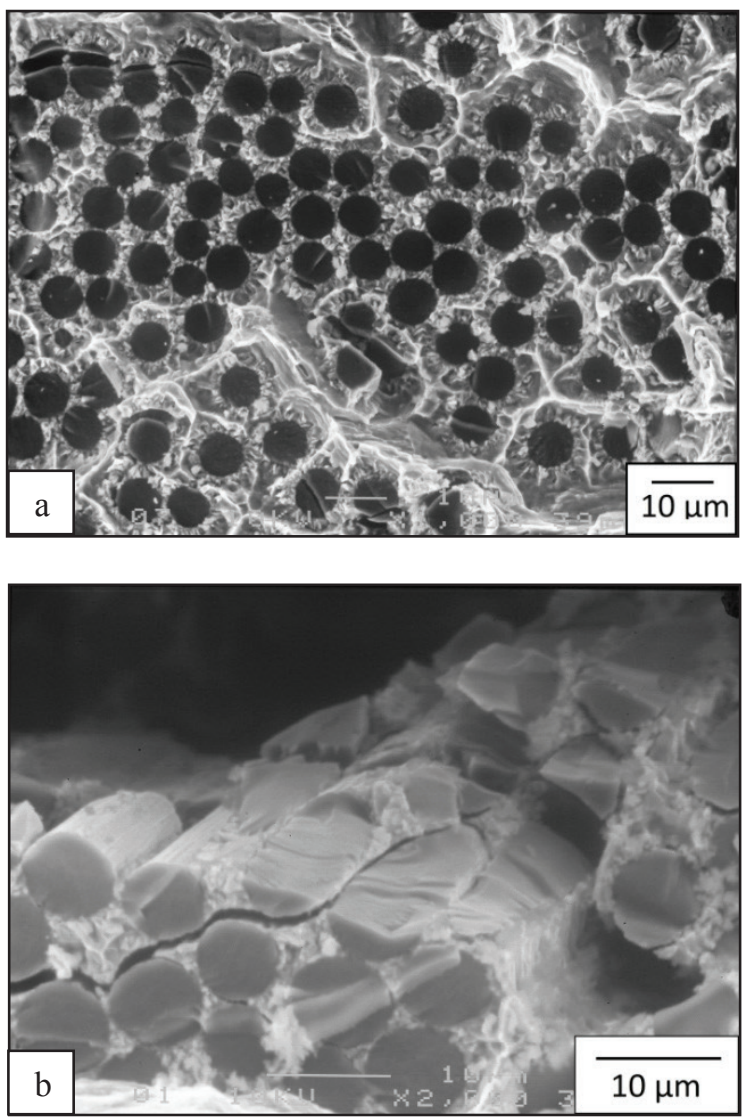

Fig. 3. Microstructure of the fracture of the composite at the sufficient infiltration pressure, combined brittle (a) and bundle (b) fracture.

It is clearly seen at a high magnification (Fig. 3, a) that the matrix completely surrounds the fibers, filling the gaps less than $1 \mu \mathrm{m}$. The fracture surface is homogeneous, there is no detachment of the matrix from the fibers. The destruction of the matrix itself is viscous. The magnesium alloy has a microcrystalline columnar structure around the fibers, which is indicative of the epitaxial nature of the crystallization. The latter circumstance in combination with the fracture character indicates to a strong bond between the fibers and the matrix.
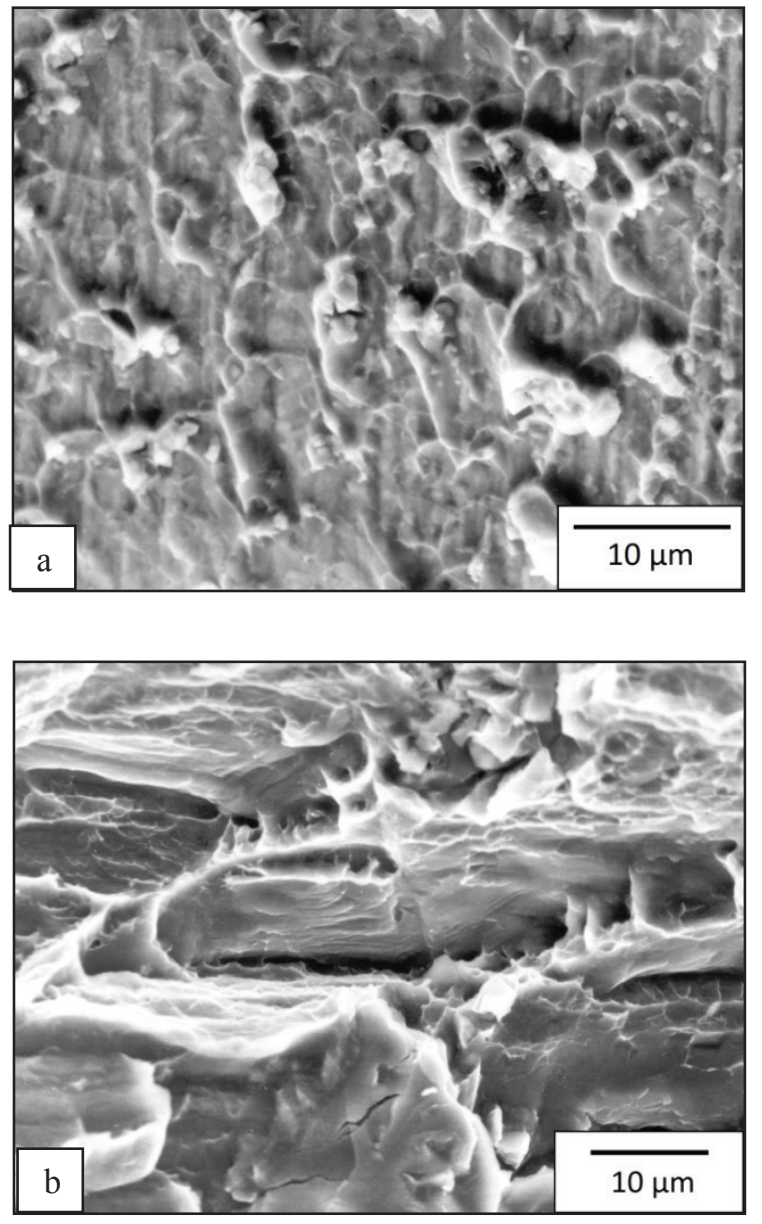

Fig. 4. The surfaces of the shell detachment from the composite matrix - the shell side (a), the magnesium alloy side (b).

The destruction nature has a complex branched relief, indicating to a high fracture energy, the fibers fail along the single surface with the matrix (Fig. 3, b). In some places there are secondary cracks that split the fiber, but the fiber does not detach from the matrix, this indicates a good strength of the matrix interaction with the fiber.

Tensile tests along the direction of fibers laying show that the destruction of the composite and the shell does not occur simultaneously. The composite is destroyed first, while the shell continues to deform plastically for some time.

The evaluation of the mechanical properties shows that at a $30 \%$ lower mass, the composite material has strength close to that of the monolithic Ti-6Al-4V alloy of about $1100 \mathrm{MPa}$.

\section{Conclusions}

Fiber reinforced lightweight materials with magnesium alloy matrices are promising to be used in lightweight applications under high dynamic and static operating loads. But it is necessary to overcome several obstacles to promote the use of magnesium matrix composites. Among them are manufacturing processes, the influence of reinforcing components, the influence of fiber on the microstructure and mechanical properties. The main 
conclusions made as a result of earlier work can be summarized as follows.

The fracture behavior of the composite material samples indicates good binding of the fiber and matrix, and at the same time there is no excessive embrittlement of the composite.

The good adhesion of the magnesium alloy to the titanium shell also contributes to the overall strength and stiffness of the product.

As a result of the work carried out, it can be concluded that the infiltration of a composite in the vacuum envelope from SMC titanium alloy by means of a press yields satisfactory results.

At the same time, economic feasibility and the most attractive specific mechanical properties can be achieved only with significant optimization of the technological process.

This method can be used to develop a technology to produce parts from magnesium-carbon composite in a protective shell.

The work was carried out using the equipment of the «Nanotech» Engineering center. http://nanotech.ugatu.ac.ru/

\section{References}

1. P. Cortes, W. Cantwell. Comp. B 37, (2006)

2. AeroMag. (2006). Aeronautical application of wrought magnesium. A proposal for the 6th European framework program. FP6-2003-Aero-1

3. R. Supplit, Th. Koch. U. Schubert. Corros. Sci, (2007).

4. A. Novikov. Composite materials in GTE parts. Aviation industry, 11, (1987) in Russian

5. A. Ivakh, A. Ryzhov, B. Galimkhanov. Bulletin of the USATU, 2, (2008) in Russian

6. W. Lacom, H.P. Degischer, P. Schulz. Key Eng. Mater. 679 (1997)

7. ASTM B94-13. (2013). Standard Specification for Magnesium-Alloy Die Castings

8. GOST 2856-79. Magnesium Casting Alloys. Grades. in Russian

9. G. Salishchev. Mechanical properties of titanium alloy VT6 with submicrocrystalline structure. Metals, 6, (1999) in Russian

10. A. Metcalfe. Interfaces in Metal Matrix Composites Vol. 1, (1974)

11. V. Vasiliev. Composite materials. Reference book. M .: Mashinostroenie. (1990) in Russian

12. V. Astanin. Microstructural design of advanced materials and composites based on them. Ufa: USATU. (2000) in Russian

13. V. Astanin. Aviation and technological systems: Interuniversity Collection of scientific papers, (2004) in Russian

14. V. Astanin, V. Astanin, Patent No. 118571. RU. (2011). in Russian 